\title{
Meeting the challenges first year engineering graphic design pre-service teachers encounter when they read and interpret assembly drawing
}

\section{Douglas Sotsaka}

Technology Education Cluster, Indumiso campus, Durban University of Technology, Pietermaritzburg, South Africa

douglassibusiso@gmail.com

https://orcid.org/0000-0003-4864-1344

\section{Asheena Singh-Pillay}

Science and Technology Education cluster, School of Education, Edgewood campus, University of KwaZuluNatal, Durban, South Africa

pillaya5@ukzn.ac.za

https://orcid.org/0000-0003-1540-8992

(Received: 13 January 2020; accepted: 4 September 2020)

\begin{abstract}
In this qualitative study, we explored the challenges first year engineering graphics and design (EGD) preservice teachers (PSTs) encounter when they read and interpret assembly drawings (ADs). Vygotsky's zone of proximal development framed this study. Purposive sampling was used to generate data from twenty-one first year EGD PSTs using a think-aloud task and individual semi-structured interviews. We subjected the data to content analysis. The findings reveal that first year EGD PSTs, when they attempt to read and interpret ADs, encounter five challenges that have implications for the teaching of EGD with regard to scaffolding the development of spatial visual ability in first year EGD PSTs.
\end{abstract}

Keywords: assembly drawing, engineering graphics and design, pre-service teachers, read and interpret

\section{Introduction}

Severe skills shortages among practicing engineers identified in the National Development Plan (National Planning Commission (2011)), have been linked directly to the schooling system despite the National Education Department's increased education budget for schools (Kraak, 2008). The failure of the schooling system to develop fundamental skills required in the engineering field such as the ability to communicate graphically, apply spatial visual reasoning, and read and interpret graphical text in subjects like engineering graphics and 
design (EGD) has been noted in studies by Sotsaka (2015) and Konadu-Yiadom (2016). It is well documented in the literature that the ability to read and interpret graphical text in engineering courses is dependent on an individual's spatial visual reasoning skills (Branoff \& Dobelis, 2012; Makgato \& Khoza, 2016). In EGD, learners learn to communicate graphically which means being able to read and interpret graphical text. A study by Singh-Pillay and Sotsaka (2017) asserted that many practising teachers of EGD lack the pedagogical content knowledge (PCK) needed to develop the spatial visual skills required by learners if they are to cope with reading and interpreting engineering drawings such as ADs. Hence, many EGD learners emerging from the schooling system (including, in this case, first-year EGD PSTs) have poorly developed or poorly activated spatial visual skills as Branoff and Dobelis (2012) have noted. Additionally, the National Senior Certificate (NSC) EGD examiners' and moderators' reports from 2011 to 2018 highlight matric learners' inability to read and interpret ADs. (Department of Basic Education (DBE), 2011-2018). Even though these NSC examiners' and moderators' reports are sent to schools the identified area of weakness pertaining to reading and interpreting AD persists. This means that practising EGD teachers are repeatedly failing to activate EGD learners' spatial visual skills. Taking into consideration the lack of PCK needed to develop spatial visual skills in practising EGD teachers, this qualitative study pays attention to first-year EGD PSTs who would have studied EGD to matric level so would have entered their teacher training course with some prior knowledge of (and preconceptions and misconceptions of) how to read and interpret an AD. ${ }^{1}$ In learning how to teach $\mathrm{AD}$, through social interactions with their lecturer and their peers, they ought to be able to improve their ability to read and interpret ADs. For lecturers in this course, gaining deeper insight into how first- year EGD PSTs read and interpret AD will assist them in scaffolding the teaching of these students about how to do so that when they qualify they will be equipped with the fundamental skills needed to activate their learners' spatial visual skills.

Knowing the challenges first year EGD PSTs encounter when they attempt to read and interpret $\mathrm{AD}$ will encourage teacher educators to explore alternative ways of teaching, and develop and design programmes to help engage PSTs and prospective learners to overcome the challenges of reading and interpreting AD. In this paper, we report on a larger qualitative study that sought to explore how first year EGD PSTs read and interpret AD. Our research question was: "What are the challenges first year EGD PSTs encounter when they read and interpret assembly drawing?"

\section{Literature review}

There is a paucity of studies in the field of EGD education. The existing literature focuses on challenges associated with students' attempts to read and interpret engineering drawings.

\footnotetext{
An assembly drawing consists of a number of different parts or components of a machine or system, along with a number of dimensions for clear interpretation. These different parts are given in 3-D and in 2-D. When these parts are interlocked, they form a complete functional machine. Assembly drawings may contain some of the following components: one or more views, including sections or auxiliaries; enlarged views to show small details, overall or specific dimensions needed for assembly, notes on manufacturing processes required for assembly; balloons to indicate item numbers; and a parts list or bill of materials (BOM).
} 


\section{Challenges associated with teaching and reading engineering drawings}

According to Perez Carrion and Serrano (2012), the high failure rate among students in their examinations in EGD and engineering courses is a result of the difficulty presented by representations of 3-D objects in 2-D that make understanding the mechanisms problematic. This shows that students have not developed their spatial ability sufficiently by the time they leave school. Chinonso (2014) found that this high failure rate is associated with traditional teaching methods that do not develop learners' spatial ability. These methods fail to emphasise the connections between the drawing and the design of the product itself. If students are to master this spatial skill, the teachers must create a learning environment in which students can engage practically in drawing activities. Furthermore, Branoff and Dobelis (2012) noted that the mismatch between engineering professors' teaching style and engineering students' learning style was the cause of the high failure rates of engineering students. This view was offered by Branoff et al. (2003) when, nearly a decade earlier, they suggested that EGD teachers must expose students to the hands-on experience of drafting techniques and conventions that meet the required standards. These competencies can be developed only by engaging students in activities that use a variety of media that offer problem-solving skills and develop the students' ability to think, see, create, and model 3-D visual images in space or on paper from 2-D blueprints. Rote learning or memorising is not and cannot be the solution to the well documented poor success rates. Moreover, Kabouridis (2010) as well as Branoff and Dobelis (2012) have recommended that EGD students should be trained specifically to develop their spatially related problem-solving abilities. When once the spatial skill is developed it should be improved continually to meet the needs of industry.

Abdullah et al. (2011) and Garmendia et al. (2007) argued that many engineering curricula do not allocate enough time to the advancement of spatial ability, in spite of this being an essential engineering skill. Typically, engineering students are given little or no formal instruction that develops their spatial abilities and educators do not teach visual-spatial thinking. Furthermore, these scholars have argued that engineering texts present static, orthogonal representations of concepts, theories, and ideas, with little or no explanation of how to interpret the spatial information, essential for the development of students' spatial ability. While the above studies have emphasised the challenges associated with teaching and reading engineering drawings they do not articulate the challenges students encounter when they read and interpret these, particularly ADs.

\section{Challenges students encounter with reading engineering drawings}

For Azodo (2017), the major challenges engineering students encounter in engineering drawing involve seeing an image in 3-D, understanding the projection view methodology, producing drawings of professional quality, and reading and interpreting engineering drawings. He explained that these challenges emanate from a lack of visualisation skills in students. Fenghong and Chikun (2011) identified that students have problems imagining the space when they have to observe the 3-D projection drawings of objects of unusual shape. They see 2-D elements in a 3-D surrounding and they visualise the 3-D environment from the 
2-D drawing, rotating objects to another plane mentally and visualizing objects in scale. These are all problems related to a lack of visualisation skills.

\section{Theoretical framework}

Vygotsky's (1978) theory of the zone of proximal development (ZPD) is widely used in studies about teaching and learning in subjects like mathematics (Siyepu, 2013) and engineering (Sotsaka, 2020). Vygotsky's ZPD focuses on the impact of social interactions during learning. For this educationalist, the development of a child is social in that the objects and people surrounding the child influence her or his cognitive development. In other words, teaching and learning are viewed as a social process during which the students bring to the process their own lived experiences grounded in their socio-cultural contexts (in this study their experiences of reading and interpreting AD from school). During the teaching and learning process, students are expected to participate actively in their own learning through the use of communication and interaction with their colleagues and instructors. The ZPD is the difference between what a student can do without help and what a student can do with help. Vygotsky conceptualised the ZPD as a way of viewing what students are coming to know over time. This means that over time children can solve problems beyond their actual developmental level if they are given guidance in the form of prompts or leading questions from someone (peer, guide, or teacher) who is at a more advanced level. Vygotsky believed that teachers should focus on teaching students within the ZPD since the best learning is that which enables one to develop within one's range of thinking. While the ZPD theory pays attention to cognitive development over a period of time, Siyepu (2013) emphasised that tasks can be used as indicators of the knowledge-skills base that the students bring into the programme in relation to a level of development. Knowing first year PSTs' actual level of development brought with them from school to university in relation to reading and interpreting $\mathrm{AD}$ will assist the lecturer to adjust her or his pedagogy, thereby providing learning interventions to scaffold first year PSTs reading and interpretation of AD, thus creating a ZPD.

Vygotsky (1978) believed that when a learner is at the ZPD for a particular task, providing the appropriate assistance will help the learner to achieve advanced understanding. According to Chaiklin (2003), Vygotsky further asserted that the students' level of development serves as a theoretical basis for appropriate pedagogical interventions including identification of specific interventions for individual students.

Since this study focuses on the challenges first year EGD PSTs encounter when they read and interpret AD, Vygotsky's notion of a ZPD is applicable. Guk and Kellogg (2007) asserted that the (potential) ZPD can be used as a mechanism to organise the learning environment of learners. Put differently, lecturers can bridge the gap between what a PST can do without help and scaffold the reading and interpreting of AD to what a PST can do with assistance.

In this study a think-loud task was used to gain insights into first year PSTs prior knowledge (or lack thereof) of reading and interpreting $\mathrm{AD}$, while a semi-structured interview was used 
to probe their justification for reading and interpreting AD the way they did. The think-aloud task allowed the lecturer to focus on the PSTs' methods of making meaning when attempting to read and interpret AD.

The notion of the ZPD takes into account individual differences among students arising from cultural and historical factors since these factors impact how individuals process information and use it. Therefore these need to be taken into account to help address the challenges identified by first year EGD PSTs in reading and interpreting AD.

\section{Methodology}

This study embraced an interpretive paradigm. According to Cohen et al. (2017), given the ontology of the qualitative interpretive paradigm, it aims to provide a better understanding of how people make sense of the contexts in which they live, work, and learn; it values the participants' subjective meaning of a social phenomenon. Qualitative research attempts to collect rich descriptive data regarding a particular real life phenomenon (in this case, the challenges first year EGD PSTs encounter when they try to read and interpret AD) in order to develop an understanding of what is being observed or studied as Yin (2014) has made clear. This study was based on the case study design. Yin (2014) described case study research as an empirical inquiry that investigates a contemporary phenomenon in its real-life context using different ways to generate data. This ensures that the issue is not explored from only one perspective, but, rather, from many which allows for multiple facets of the phenomenon to be revealed and understood as Baxter and Jack (2008) have suggested. The specified criteria of the case study design require that participants be purposively selected; here they had to be first-year EGD PSTs. There were 21 first year PSTs (11 females and 10 males) here referred to as P1, P2 etc, enrolled in 2018 at a South African university of technology to train as teachers of EGD. We obtained informed consent from the participants and the university concerned and have ensured their anonymity and confidentiality throughout.

Data was generated in two stages. Stage one involved the use of a think-aloud task ${ }^{2}$ on reading and interpreting $\mathrm{AD}$. The lecturer involved designed the think-aloud task activities to begin with what the first year EGD PST ought to be able to do independently, based on prior knowledge. This was done with the object of linking this already existing knowledge with new knowledge of what they would be able to perform with assistance. The task was thus based on an EGD matric examination question since the content covered in it points to the foundation of learning EGD at university. The think-aloud task was comprised of four sections and lasted for an hour. It required PSTs to identify different sectional views ${ }^{3}$ of small and large parts, use data provided in the title block, consider notes outside the title block, and mentally manipulate parts to see how they fit together in order to be assembled. This task

Think-aloud is a research method in which participants speak aloud any words in their minds as they complete a task. We video recorded students' engagement with the task for observation purposes.

Sectional view: A sectional view or a section looks inside an object. Sections are used to clarify the interior construction of a part that cannot be clearly described by hidden lines in exterior views. By taking an imaginary cut through the object and removing a portion, the inside features may be seen more clearly. 
recalled and applied the South African National Standards ${ }^{4}$ (SANS) code of practice (South African Bureau of Standards,1993, para. 6) requiring students to "measure and draw all parts in 3rd angle orthographic projection as per given dimensions, plan the layout of the paper by identifying the position of each view as per the question, and use correct line types in the drawing." Participants were asked to say whatever came into their minds as they completed the task. This might have included reference to what they were looking at, thinking, doing, and feeling while completing it. This allowed us an insight into the first year EGD PSTs' cognitive processes as they attempted to read and interpret the AD in the think-aloud task (rather than considering only their final product) and helped to make sense of these articulated processes. Three groups of seven participants each completed the task in different parts of the same room. This was done in order to promote collaborative learning during the task-based activity, to scaffold learning, to enable students to work at their own pace as well as serve as a mechanism for judging the lower level of ability within each group. The advantage of using a think-aloud task here was that first year EGD PSTs were engaged in a real activity that provided us with their ongoing cognitive processes instead of our eliciting data by asking each participant how they would complete the activity, without actually engaging in it. All the groups were video recorded to allow us to revisit each, in line with Cohen et al. (2017) who noted that video recordings allow for repeated viewing and checking. The video recordings were transcribed verbatim and sent to participants for member checking and were used for retrospective probing during the second stage of data generation that involved a recorded semi-structured interview with each first year EGD PST after the task-based activity. This allowed the first author to further probe the participants' responses and reactions to them.

Prior to data analysis the think-aloud task was assessed to identify areas of strength and weakness in how the PSTs read and interpreted the AD. The transcripts of the video recordings of the task and the interviews were subjected to content analysis. Transcripts were read and re-read before coding began. To establish codes the following three questions related to reading the transcripts were asked: What is foregrounded? How is it foregrounded? Why it is foregrounded?

\section{Findings and discussion}

The analysis revealed that first-year EGD PSTs encountered five major challenges when they read and interpreted AD during the think-aloud task: inability to read and interpret information in the title block; inability to differentiate orthographic and isometric projection and visualise the different views; inability to visualise, see spatial relationships between objects, and rotate objects; inability to measure accurately and apply SANS code of practice; and inability to assemble and recognise lines.

$4 \quad$ SANS-regulations and codes of practice for drawing structures. 


\section{Inability to read and interpret information in the title block}

The majority of first year EGD PSTs were unable to use all the visual and textual information in the title block when they attempted to read and interpret the AD in the think-aloud task. The title block contained the following information: the title; a description of the object in the $\mathrm{AD}$; the type of projection; the drafting standard used; and the scale of drawing and dimension. Data from the semi-structured interviews was used to illuminate how first year EGD PSTs used (or failed to use) the information from the title block and their inability to read and interpret visual information. The excerpts below from two semi-structured interviews reveal how the information from the title block was used by PSTs.

I have forgotten how to make sense of the given information. I remember my high school teacher saying that this is the starting point, but I don't know how or why. I tried looking around to see what other students were doing but it did not help. It is easier to read words rather [than] diagrams. I have no visual skills; I learn by reading. (P4)

It is given that the isometric exploded drawing of the parts can be assembled. Scale is 1: 1 . It is in the third angle, but sometime[s], when you read these thing[s] you just read them. The words remain foreign [and] you don't get any clue of how or where or when to use this information. These terms are so hard to understand and remember. (P1)

Data from the recorded observation of the think-aloud task echoes these participants' observations.

I got the title so I can recognise the drawing. That's one mark, but what to do with the other information? I just get so stressed when I see all these drawings. Where do I use it and how? I wish I paid more attention at school. I barely passed EGD. It's so difficult to understand and read the diagrams. (P7)

The excerpts above reveal that first year EGD PSTs were unable to interpret the information in the title block. They were unable to decode, interpret, and evaluate this text so could not use it to make sense of the accompanying visual text. Furthermore, they were unable to understand the concepts used in the title block and visual text. Studies by Azodo (2017) and Akasah and Alias (2010) have revealed that first year engineering students have difficulty reading and interpreting visual text and prefer tasks that have written text. It is evident that the first year EGD PSTs' inability to process the information and understand the terms used in the title block gives rise to anxiety that affected their ability to see the link between the text in the title block and the visual text. Here, their prior learning experiences of AD in school become apparent. For these PSTs their level of potential to learn to read and interpret AD is negligible. Their preference for written text as opposed to visual text explains the anxiety they experience when engaging with visual text. This preference for written text points to the kind of intervention, the instructions, and the activities necessary if we are to scaffold their 
learning to read and interpret AD since, as Vygotsky argued, development is enhanced by instruction because instruction creates the zone of proximal development.

Inability to differentiate orthographic and isometric projection and visualise the different views

Difficulties in differentiating between orthographic and isometric projection as well as understanding the structure of 3-D objects from different views were encountered by most of these PSTs as is made clear in the excerpts below from the interviews.

I find it very difficult to imagine drawings in 3-D. I try so hard [so] if someone could train me how to do this, I will learn what must I do first. I will go with my gut feeling. I don't have a strategy to solve this. (P3)

I lack imagination, I can't see things mentally. I need to see an object physically to understand its structure in different views. I will try and see what works [but] it's frustrating not knowing for sure. (P14)

Similar views were expressed during the think-aloud task.

How do I imagine a drawing in 2-D to its 3-D form, and how must I draw from a certain angle when I can't imagine the shape? I need to know what steps I must follow. I didn't learn this at school. This is ... [breaks his pencil and swears]. (P15)

The above excerpts illuminate three major problems first year EGD PSTs carry with them from the school EGD context to university and the factors that impeded their ability to differentiate orthographic and isometric projection and visualise the different views. In terms of ZPD their actual level of development is exposed. The first challenge is their lack of familiarity with the nomenclature of EGD, which results in the inability to differentiate between basic concepts such as orthographic and isometric projection as well as 2-D and 3-D drawings. Thus, an EGD way to talk and think about AD is, at the outset, outside the first year EGD PSTs' ability. This inability to understand foundational concepts points to the lack of a knowledge base and skills. Of course, understanding the basic key concepts in EGD necessarily forms the foundation for all future learning in EGD, so, without such understanding, further learning is impeded. It is apparent that future teaching and learning activities need to focus on the nomenclature of EGD to help PSTs make meaning of this language in relation to the visual text of $\mathrm{AD}$ so as to scaffold their reading and interpretation of $\mathrm{AD}$ and thereby develop their higher cognitive functions.

The second challenge when these first year EGD PSTs attempted to read and interpret AD was that of visualising images given to them in different views. Most of them were unable to visualise or comprehend the visual information. Visualisation is a way of thinking that results in the formation of mental images. This means that for first year EGD PSTs to be able to visualise objects they need to be able to imagine objects in different views. In this regard it is worth noting that Felder and Silverman (1998) have purported that the ability to form mental images is dependent on a person's mental schema. Thus, it can be argued that these first year 
EGD PSTs either do not have the requisite mental schema or are unable to use it to visualise and develop the view or image/s of an object just as they had to do in the think-aloud task, so they need exercises in visualisation of 3-D and 2-D objects.

The third challenge is the lack of a systematic method to analyse visual information.

Furthermore, these first year EGD PSTs confirmed that they do not have a problem-solving strategy in place (P3 said, "I don't have a strategy to solve this"), and that they use the trialand-error strategy (P14 said, "try and see what works") or they rely on intuition (P3 said, "my gut feeling") when they have to read and interpret AD.

It is evident that these PSTs have inadequate visualisation skills and that this hinders learning how to read and interpret AD. If first year EGD PSTs are unable to visualise they will not be able to master the rest of the content of the module. The above findings resonate with studies by Azodo (2017) and Ali and Nordin (2012). These quantitative studies highlighted that firstyear engineering students encounter difficulties with visualisation when they are engaging with engineering drawings despite having studied EGD at school level. A study by Garmendia et al. (2007) revealed that the inability to visualise could be attributed to the teaching strategy used in most classrooms which consists of visualisation problems being followed by the solutions to those problems, without any explanation of how to solve them or the reasoning needed during the problem-solving process. Vygotsky believed that teachers should focus on teaching students within a ZPD by using such appropriate teaching strategies.

Inability to visualise, see relationships between objects, and rotate objects

All these first year EGD PSTs struggled to visualise and see spatial relationships between objects as well as rotate objects as is clear in the excerpts below from the semi-structured interviews.

I can see the one view that is drawn, but I battle to imagine the sides that are not drawn. I also cannot see the relationship between some objects. I am hopeless. I want to quit this course before we get any further and it becomes more difficult. This 2-D 13-D stresses me. (P11)

I can physically flip an object that is physically in front of me [but] I cannot mentally flip an object, nor can I imagine the hidden sides of an object or imagine how they fit together. With large objects I can try but [with] the smaller object that is almost impossible. I can't imagine [how] to assemble the small part. It's easier to do it physically. (P17)

It is hard to draw from certain angles as I cannot imagine the shape or view required. (P6)

The data from the recorded observations of the think-aloud task confirms the existence of these challenges. 
Oh god how I hate these drawings. It is a disaster [bangs the table looks around, shakes his head]. I also find it hard to see the movement of all these parts in my head. It is not so easy to imagine how the parts will fit together. (P4)

I can recognise a washer here, but I am not sure how to rotate this. I see the difference between the bolt and nut now. I am not sure which sides of the bolt and nut to draw in front view to produce 3rd angle as required by the question. I will lose marks in this section. This is hell. (P8)

The excerpts above illuminate the fact that EGD requires advanced visualization skills that include the ability to see the relationship between the objects portrayed in the diagram, and the ability to rotate objects mentally. Furthermore, the excerpts demonstrate that first year EGD PSTs who lack these skills encounter difficulties in imagining or visualizing the objects or views. They are unable to use the visual information in the think-aloud task to exercise visual discrimination, visual figure ground discrimination, visual sequencing, and visualmotor processing, as well as (re)organising the information to create an understanding of meaningful patterns. First year EGD PSTs' inability to see the relationship between the objects portrayed in the diagram and to rotate objects mentally has an impact on their performance of the task and on their emotional state. The anxiety experienced as well as the severe challenge first year EGD PSTs encounter when they read and interpret AD impedes their ability to form mental images and translate them into drawings. These findings highlight the effects of the prior learning experiences of reading and interpreting AD that first year EGD PSTs carry with them from high school to university. Furthermore, the above findings resonate with Vygotsky's ideas that teaching and learning is a social process and that, in this case, the students bring to the process their own lived experiences of reading and interpreting AD or of being unable to do so. First year EGD PSTs are unable to construct pictorial images of the objects in their minds and translate the images into engineering sketches and multiview drawings. Further, they are unable to differentiate between small and large parts. These findings pertaining to visual skills, mentally rotating objects, and drawing resonate with those of Gorska and Sorby's (2008) study that found that the predominant challenges engineering students encounter in engineering drawing are difficulties in seeing an image in 3-D and in manipulating objects mentally. In addition, the visual skills needed for manipulating small and large objects seem to differ. First year EGD PSTs' failure to visualise and manipulate objects mentally ties in with results from other international studies. For example, Riza and Seda (2017) have argued that to be able to draw objects correctly from different views requires an understanding of the relationship between shape and form. Along similar lines, Fenghong and Chikun (2011, p. 563) contended that "the student should do the space imaging to construct the space conception" when selecting the correct expression of parts. This means that models could help engineering students to visualise and thus nurture their spatial ability. Spatial ability is not a fixed innate quality as proposed by Piaget (1973) but is, rather, malleable in people of all ages, and training generally has a positive and permanent impact on them (Uttal \& Cohen, 2012). Samsudin et al., (2011) found that secondary school students performed better at a given orthographic drawing task after they received spatial visualisation training. Proper instructions from the teacher together with a learning environment that 
promotes cognitive interaction among peers when engaging in reading and interpreting of AD can scaffold learning and can create the much needed ZPD for first year EGD PSTs who have poor spatial visual skills, and are not visual learners.

\section{Inability to measure accurately and recall the SANS code of practice}

The skill of measuring accurately and applying the SANS code of practice is very poor among the majority of first year EGD PSTs as can be gathered from the excerpts below from their interviews.

It would have been easier if you were to just draw as you see it on the exploded drawing, but now the problem is that you have to construct the bolt [so] you need to know how to construct [it]. The new measurements must be accurate, so it becomes a bit complicated when it comes to that. (P2)

The data from the think-aloud task confirms the challenge encountered by these PSTs when measuring and applying the SANS code of practice.

Shucks! Do I measure from the edge of the ruler or the first marking on it? I always measure from the edge of the ruler, but I think this teacher was saying from the first marking on the ruler (flings his ruler on the desk in frustration). This is confusing, I wish I could quit ... Hey can you help me here? Do you know how to do this? I also don't know this SANS code. (P19)

This task is bit difficult and I am not able to remember the . . . I can see here I am required to do construction of bolt and nut. Eish! I cannot remember how to do calculations in order to do the construction of bolt. Don't know where to start now. I wish someone can help me. (P5)

The excerpts confirm that first year EGD PSTs encounter difficulties with measurements and with recalling the SANS codes and some tried to get help from peers while completing the think-aloud task but since they all came into university with similar experiences of learning to read and interpret AD they were unable to assist each other. Vygotsky (1978) asserted that higher mental functions are integrally tied to social interaction where individuals learn from more abled peers in a group. Accurate measurement is the most fundamental element on which engineering drawings depend. First year EGD PSTs' inability to measure accurately has implications for the kind of teaching activities (measurements and reading to scale) and knowledge base that needs to be developed in them to scaffold their learning with regard to reading and interpreting $\mathrm{AD}$.

\section{Inability to assemble parts and draw different lines}

Lines in EGD can be construed as letters in written text. Lines enable a person to describe the external as well as the internal features of an object. Since each symbolic line in the drawing represents a particular aspect, it is very important that they are drawn in a standardised format. First year EGD PSTs are expected to know line types acceding to the SANS code of 
practice. The excerpts below, the first from an interview and the second from the think-aloud task, bring to the fore the challenges these EGD first year PSTs encountered with line work.

I can see that there are centre lines, but I have no idea where to draw the other lines. Physical components can help to see this thing. . . (P1)

Drawing centre lines is not that difficult but I need to identify how many that I must draw such that they are seen as centre lines and in correct position in the whole drawing. I might get some mark for these part assembled, but I am worried about my line work, erasing them and starting all over again might take time. (P20)

It is evident that first-year EGD PSTs' lack of knowledge about the SANS code of practice impedes their ability to read, interpret, and draw AD. The deficit in terms of line work suggests that future teaching activities need to foreground line-work as well as the connectivity in each part of the complete mechanical assembly drawing.

\section{Conclusion}

First year EGD PSTs encountered the five key challenges discussed above when they were attempting to read and interpret AD.

The challenges encountered by these first year EGD PSTs were inextricably linked to their lack of visualisation skills which compounds their inability to grasp how mental images are defined, produced, or transformed. Skills which, according to Sorby et al., (2013) are part of higher-level thinking, reasoning, and creativity that are related to abilities such as spatial visualisation, mental rotation, and spatial perception. Since students come into the EGD course with insufficient content background, more attention ought to be paid to Vygotsky's notion of teaching and learning as a social process. Teachers ought to focus on teaching students within their own ZPD bearing in mind students' learning styles in order to alter what PSTs cannot do without assistance in favour of what they can.

The findings of this study have implications for the need for teacher education programmes to strengthen the specific subject didactics of technology subjects in order to prepare adequately the teachers of EGD and related subjects.

The limitation of this study is that it was based on one university so the results may not be generalisable to all PSTs in an EGD course countrywide.

Based on the findings of this study we suggest the need for large-scale research that would include all pre-service teachers in the EGD course across all South African universities offering the Bachelor of Education programme, with a view to understanding the challenges experienced by students in this course. 


\section{References}

Abdullah, Z., Field, B. W., \& Burvill, C. R. (2011). Measuring Malaysian undergraduate skills in reading and interpreting engineering drawing. In S. J. Culley, B. J. Hicks, T. C. McAloone, T. J. Howard \& B. Ion (Eds.), 18th international conference on engineering design: Impacting society through engineering design (Vol. 8) (pp. 1322). ICED Publishers.

Akasah, Z. A., \& Alias, M. (2010). Bridging the spatial visualisation skills gap through engineering drawing using the whole-to-parts approach. Australasian Journal of Engineering Education, 16(1), 81-86.

Ali, D. F., \& Nordin, M. S. (2012). Visualization skills among Universiti Teknologi Malaysia students. International Journal of Information and Education Technology, 2(4), 371373.

Azodo, A. P. (2017). Attitude of engineering students towards engineering drawing: A case study. International Journal of Research Studies in Education, 6(1), 61-74.

Baxter, P., \& Jack, S. (2008). Qualitative case study methodology: Study design and implementation for novice researchers. The Qualitative Report, 13(4), 544-559.

Branoff, T. J., \& Dobelis, M. (2012). Engineering graphics literacy: Measuring students' ability to model objects from assembly drawing information. Engineering Graphic Design Journal, 76(3), 37-43

Branoff, T. J., Hartman, N. W., \& Wiebe, E. N. (2003). Constraint-based, three dimensional solid modeling in an introductory engineering graphics course: Re-examining the curriculum. Engineering Design Graphics Journal, 66(1), 5-10.

Chaiklin, S. (2003). The zone of proximal development in Vygotsky's theory of learning and school instruction. In A. Kozulin, B. Gindis, V. S. Ageyev \& S. M. Miller (Eds.), Vygotsky's educational theory in cultural context (pp. 39-64). Cambridge University Press.

Chinonso, O. U. (2014). Management of woodwork workshop in Nigerian tertiary institutions. Malaysian Online Journal of Educational Management, 2(1), 20-36.

Cohen, L., Manion, L., \& Morrison, K. (2017). Research methods in education (10th ed.). Routledge.

Department of Basic Education, DBE (2011; 2012; 2013; 2014; 2015; 2016; 2017; 2018). National senior certificate Engineering Graphics and Design Examiners' reports. Department of Education. 
Felder R. M., \& Silverman, L. (1998). Learning and teaching styles in engineering education. Engineering Education, 78(7), 674-681.

Fenghong W., \& Chikun, C. (2011). Improve engineering drawing teaching by combining modern methods and traditional methods. In W. Karwowski \& T. Ahram (Eds.), IEEE International Symposium on IT in Medicine and Education (Vol. 1) (pp. 563-566). IEEE Corporate.

Garmendia, M., Guisasola, J., \& Sierra, E. (2007). First-year engineering students' difficulties in visualization and drawing tasks. European Journal of Engineering Education, 32(3), 315-322.

Gorska, R., \& Sorby, S. (2008, June). Testing instruments for the assessment of 3 D spatial skills. Paper presented at the American society for engineering education annual conference, Pittsburgh, USA. http://soa.asee.org/paper/conference/paperview.cfm?id=9408

Guk, I., \& Kellogg, D. (2007). The ZPD and whole class teaching: Teacher-led and studentled interactional mediation of tasks. Language Teaching Research, 11(3), 281-299.

Kabouridis, G. (2010). An innovative approach to face the first-year mechanical engineering students' conceptual difficulties in engineering design. In D. Nguyen \& D. Pudlowski (Eds.), Proceedings of $1^{\text {st }}$ World institute for engineering and technology education annual conference on engineering and technology education (Vol. 1) (pp 110-113). Wiete Publishers.

Konadu-Yiadom, E. (2016). An exploration of quantity surveying students' engagement with engineering graphics and specification drawings [Unpublished master's dissertation]. University of KwaZulu-Natal, Durban, RSA.

Kraak, A. (2008). Incoherence in the South African labour market for intermediate skills. Journal of Education and Work, 21(3), 197-215.

Makgato, M., \& Khoza, S. (2016). Difficulties experienced by pre-service teachers and lecturers in engineering graphics and design course at a university in South Africa. International Journal of Educational Science, 14(12), 157-166.

National Planning Commission (NPC). (2011) National Development Plan 2030: Our future - make it work. National Planning Commission, Office of the Presidency.

Perez Carrion, T., \& Serrano, M. (2012). Ejercicios para el desarrolo de la perception especial. [Exercise for the development of spatial perception.] Editorial Club Universitario.

Piaget, J. (1973). To understand is to invent. Viking Press. 
Riza, A. A., \& Seda, D. S. (2017). Technical drafting and mental visualization in interior architecture education. International Journal for the Scholarship of Teaching and Learning, 11(2), 1-8.

Samsudin, K., Rafi, A., \& Hanif, A. S. (2011). Training in mental rotation and spatial visualization and its impact on orthographic drawing performance. Journal of Educational Technology \& Society, 14(1), 179-186.

Singh-Pillay, A., \& Sotsaka, D. (2017). Engineering and design teachers' understanding and teaching of assembly drawing. EURASIA Journal of Mathematics Science and Technology Education, 13(5) 1213-1228.

Siyepu, S. (2013). The zone of proximal development in the learning of mathematics. South African Journal of Education, 33(2), 1-13.

Sorby, S. A., Casey, B., Veurink, N., \& Dulaney, A. (2013). The role of spatial training in improving spatial and calculus performance in engineering students. Learning and Individual Differences, 26, 20-29.

Sotsaka, D. (2015). An exploration of the interface between Grade 11 engineering graphics and design teachers' understanding of assembly drawing and their practice: A case study of the uThukela district, KwaZulu-Natal [Unpublished master's dissertation]. University of KwaZulu-Natal, Durban, RSA.

Sotsaka, D. (2020). Unmasking how pre-service engineering graphics and design teachers read and interpret assembly drawing at a University of Technology: A case study in Umgungundlovu, KwaZulu-Natal [Unpublished doctoral dissertation]. University of KwaZulu-Natal, Durban, RSA.

South African Bureau of Standards. (1993). South African national standard code of practice. Engineering drawing SABS 0111-1. South African Bureau of Standards.

Uttal, D. H., \& Cohen, C. A. (2012). Spatial thinking and STEM education: When, why, and how? Psychology of Learning and Motivation, 57, 147-181.

Vygotsky, L. S. (1978). Mind in Society: The development of higher psychological processes. Harvard University Press.

Yin, R. K. (2014). Case study research: Design and methods (5th ed.). SAGE. 